\title{
Analytical Comparison of Dual-Input Isolated dc-dc Converter with an ac or dc Inductor for Renewable Energy Systems
}

\author{
Zhang, Zhe; Mira Albert, Maria del Carmen; Andersen, Michael A. E.
}

Published in:

IEEE International Future Energy Electronics Conference 2017

Link to article, DOI:

10.1109/IFEEC.2017.7992117

Publication date:

2017

Document Version

Peer reviewed version

Link back to DTU Orbit

Citation (APA):

Zhang, Z., Mira Albert, M. D. C., \& Andersen, M. A. E. (2017). Analytical Comparison of Dual-Input Isolated dcdc Converter with an ac or dc Inductor for Renewable Energy Systems. In IEEE International Future Energy Electronics Conference 2017 (pp. 659-664). IEEE. https://doi.org/10.1109/IFEEC.2017.7992117

\section{General rights}

Copyright and moral rights for the publications made accessible in the public portal are retained by the authors and/or other copyright owners and it is a condition of accessing publications that users recognise and abide by the legal requirements associated with these rights.

- Users may download and print one copy of any publication from the public portal for the purpose of private study or research.

- You may not further distribute the material or use it for any profit-making activity or commercial gain

- You may freely distribute the URL identifying the publication in the public portal 


\title{
Analytical Comparison of Dual-Input Isolated dc-dc Converter with an ac or dc Inductor for Renewable Energy Systems
}

\author{
Zhe Zhang, Maria C. Mira and Michael A. E. Andersen \\ Department of Electrical Engineering \\ Technical University of Denmark (DTU) \\ Kgs. Lyngby, Denmark \\ zz@elektro.dtu.dk, mmial@elektro.dtu.dk, ma@elektro.dtu.dk
}

\begin{abstract}
This paper presents two configurations of dualinput (DI) or three-port (TPC) isolated dc-dc converters for hybrid renewable energy systems such as photovoltaics and batteries. These two converters are derived by integrating an interleaved boost converter and a single-active bridge converter with an ac inductor as a power interfacing element or phase-shift softswitching converter with an output dc inductor. Both converters are controlled by a pulse-width modulation and phase-shift hybrid modulation scheme. The two converter topologies are, even though quite similar from the topological and control perspective, distinct in operation principles, voltage/power transfer functions, loss distributions, soft-switching constraints, and power efficiency under the same operating conditions. Moreover, the inductor design differs greatly between these two cases. In this paper, a comprehensive comparison is given for the first time and thereby the corresponding design tradeoffs are discussed. Finally, a laboratory $1 \mathrm{~kW}$ prototype is constructed and tested to verify the theoretical analysis.
\end{abstract}

Keywords-Converter; dc-dc; multiple inputs; renewable energies; soft swtiching.

\section{INTRODUCTION}

Applying clean and renewable energies, such as wind energy, solar and hydrogen, has become a research focus in academia and industry over the last decades [1]-[3]. Due to the intermittent feature of renewable energy sources, energy storage units are needed to fill up the gap between electricity generation and consumption. Moreover, hybridizing energy sources can distinctly improve system performance in terms of decreasing cost, isolating energy sources from load fluctuations and enhancing dynamics. Hence, hybrid energy conversion systems are well suited for the applications in which the average power demand is low, whereas the load dynamics are relatively high [4]-[6]. For instance, [3] presented and compared different power electronic interfacing solutions for a reversible fuel cell with auxiliary power sources (APS) to overcome the drawbacks of fuel cell systems such as slow dynamics. Moreover, in order to efficiently regulate output voltage, which normally has large voltage difference from input ports, as well as to provide galvanic isolation, many fully or partially isolated three-port dcdc converters with high frequency transformers have been proposed and studied in recent years [7]-[14]. An example of forming a partially isolated converter with two input voltage sources is illustrated in Fig. 1. The topology proposed in [8] and

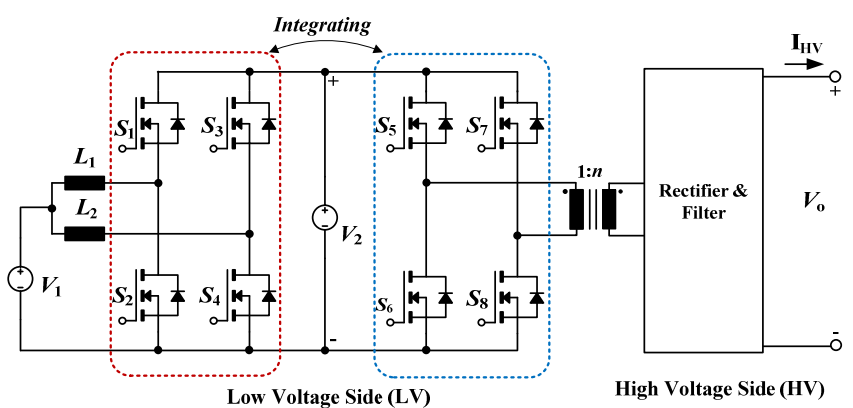

Fig. 1. Derivation of partially isolated three-port converter (TPC).

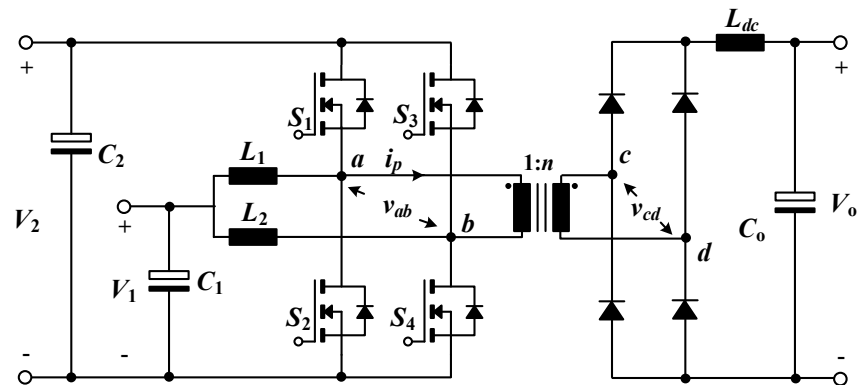

(a)

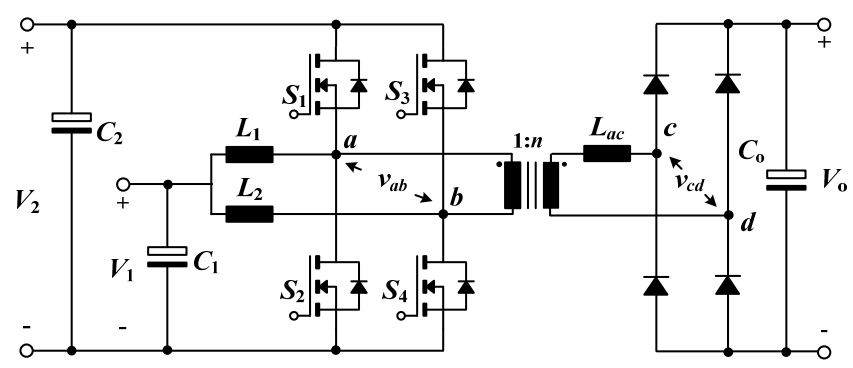

(b)

Fig. 2. Topologies of two dual-input (DI) converters. (a) dc-inductor based topology, and (b) ac-inductor based topology. 


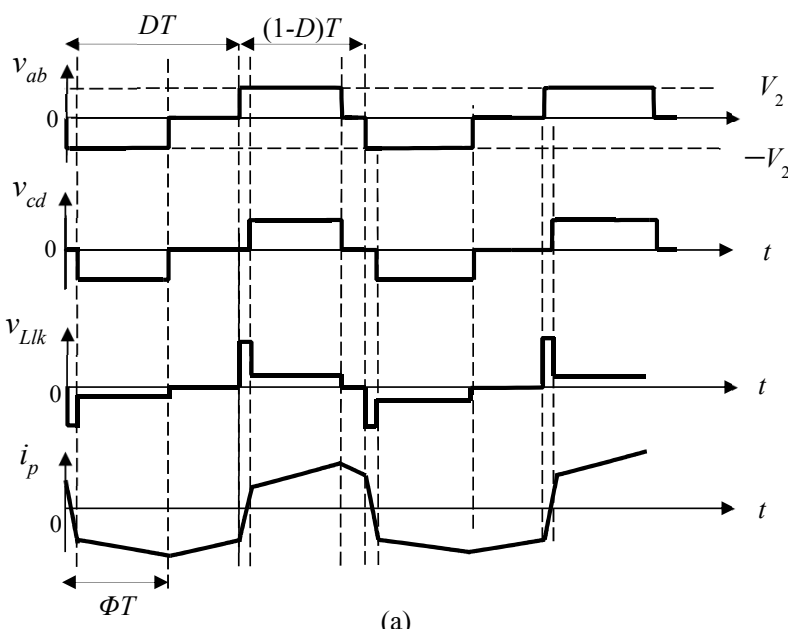

(a)

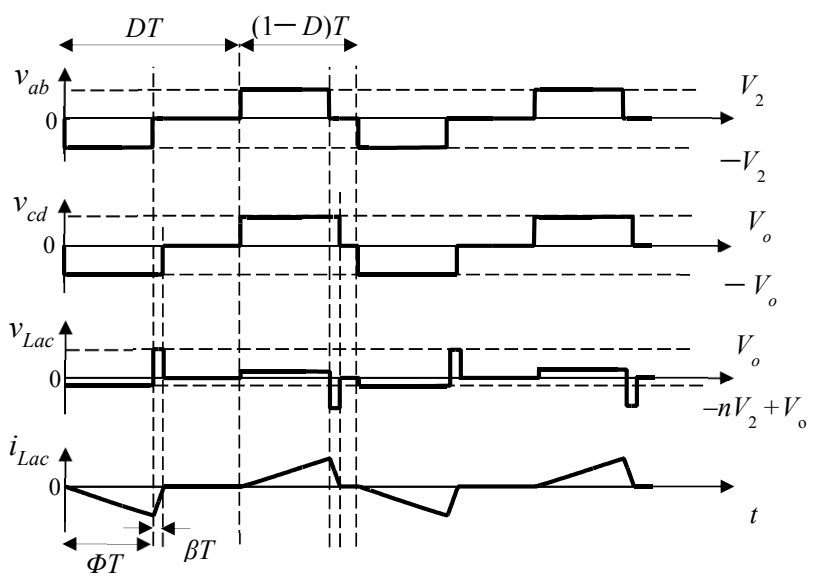

(b)

Fig. 3. Typical waveforms of the studied topologies: (a) dc-inductor based topology, and (b) ac-inductor based topology.

[9] and its derivations were obtained by integrating a two-phase interleaved boost converter into a phase-shift full-bridge (PSFB) converter, as shown in Fig. 2 (a), where an LC filter is implemented at the output port. The major drawbacks for PSFB converters, such as duty cycle losses due to leakage inductance, large circulating current during freewheeling periods and limited zero-voltage switching (ZVS) for the lagging-leg switches have been studied in the last decade. Moreover, in buck-type topologies the rectifier diodes must be able to block a voltage higher than the dc output, thereby, leading to high losses in applications such as single-phase or three-phase grid-connected systems where $400 \mathrm{~V}$ or $800 \mathrm{~V}$ dc-link voltages, respectively, are required. An alternative topology, shown in Fig. 2 (b), based on an ac inductor was studied in [14] and [15]. Since the acinductor based converter is derived from the dual-active-bridge (DAB) converters, the operating waveforms, loss distribution, and soft-switching operation are different from that of the dcinductor configuration in Fig. 2 (a). In this paper, the two topologies with either dc or ac inductor are investigated and compared comprehensively based on the same specifications.

\section{OPERATION PRINCIPLES}

Comparing Fig. 2 (a) with Fig. 2 (b), it can be seen that the only difference is the location of the inductor employed on the secondary side. In these two converters, even though the switches are controlled by the same method, i.e. pulse-widthmodulation (PWM) plus duty cycle control, the operating waveforms are different as illustrated in Fig. 3.

From the key waveforms shown in Fig. 3 it can be observed that if the phase-shift angle, $\Phi$, is kept smaller than the duty cycle $(D)$ and its complement $(1-D)$, i.e. $\Phi<\min [D,(1-D)]$, the two control parameters, duty cycle $D$ and phase-shift angle $\Phi$, are completely decoupled. Therefore, in this operation mode the energy transferred to the output port is not directly regulated by the duty cycle. Instead, the power between $V_{1}$ and $V_{2}$ is controlled by $D$ and the power flow delivered to the output port is regulated by $\Phi$ as shown in (1)-(5).

The relationship between $V_{1}$ and $V_{2}$ is governed by the voltage gain of a boost converter as:

$$
V_{2}=\frac{V_{1}}{1-D} \text {. }
$$

Correspondingly, the output voltage $\left(V_{\mathrm{o}}\right)$ for the dc-inductor and the ac-inductor based topologies can be derived from the typical operating waveforms in Fig. 3 as shown in (2) and (4), respectively, where $n$ is the transformer turn ratio defined as $N_{s}: N_{p}$.

$$
\begin{gathered}
V_{o_{-} d c_{-} \text {ind_based }}=\frac{2 \cdot n \cdot V_{2}}{1+m} \cdot \Phi . \\
m=4 \cdot n^{2} \cdot L_{l k} \cdot R_{L} \cdot T<<1
\end{gathered}
$$

where $L_{l k}, R_{L}$ and $T$ represent the leakage inductance, the equivalent load resistance, and the switching period, respectively.

$$
\begin{gathered}
V_{\text {o_ac_ind_based }_{-}=} \frac{n \cdot V_{2}}{k} \cdot \Phi \cdot\left(\sqrt{\Phi^{2}+2 k}-\Phi\right) \\
k=\frac{2 \cdot L_{a c}}{R_{L} \cdot T}
\end{gathered}
$$

\section{COMPONENT STRESS FACTOR (CSF) ANALYSIS}

To compare different topologies under certain conditions, component stress factors (CSFs) can be used to indicate the converter stresses and thereby show a quantitative measure of converter performance [17]. CSF analysis is based in the assumption that the studied topologies must have the same amount silicon, magnetic material and capacitor volume. Therefore, three separate components i.e. the semiconductor component stress factor (SCSF), the winding component stress factor (WCSF) as well as the capacitor component stress factor (CCSF) can be defined in (6)-(11), respectively.

$$
\operatorname{SCSF}_{i}=\frac{\sum_{i} W_{i}}{W_{i}} \cdot \frac{V_{\max }{ }^{2} \cdot I_{r m s}{ }^{2}}{P_{\text {out }}{ }^{2}}
$$




$$
\begin{aligned}
W C S F_{i} & =\frac{\sum_{i} W_{i}}{W_{i}} \cdot \frac{V_{\text {max_avg }}{ }^{2} \cdot I_{r m s}{ }^{2}}{P_{\text {out }}{ }^{2}} \\
C C S F_{i} & =\frac{\sum_{i} W_{i}}{W_{i}} \cdot \frac{V_{\max }{ }^{2} \cdot I_{r m s}^{2}}{P_{\text {out }}{ }^{2}} \\
S C S F & =\sum_{i} S C S F_{i} \\
W C S F & =\sum_{i} W C S F_{i} \\
C C S F & =\sum_{i} S C S F_{i}
\end{aligned}
$$

where $W_{i}$ is the amount of resources assigned to the specific component, which represent a weighting factor. For instance, to optimize the converter in terms of different CSF values, the weighting factors can accordingly be distributed differently. However, in this paper the resources are distributed equally to simplify the analysis.

Since the two-phase interleaved boost structure in both topologies is the same in terms of configuration and operation principle, regardless of whether a dc or an ac inductor is used, the CSF analysis will be performed on the circuit configuration from the input $V_{2}$ to the output port $V_{\mathrm{o}}$.

For CSF analysis it is assumed that converter is ideal and lossless, and the inductor and the capacitors are large enough so that all the ripples are negligible. For the dc-inductor based topology, the root mean square (rms) current of the low voltage side switches can be calculated as in (12).

$$
I_{r m s_{-} S 1, S 3}=n \cdot \frac{P_{\text {out }}}{V_{o}} \cdot \sqrt{1-D} ; \quad I_{r m s_{-} S 2, S 4}=n \cdot \frac{P_{\text {out }}}{V_{o}} \cdot \sqrt{D}
$$

The voltage stress in the windings is calculated as

$$
V_{\text {max_avg }}=\frac{\int_{0}^{T}\left|V_{\text {winding }}\right| d t}{T}
$$

where $V_{\text {winding }}$ represents the voltage across the windings.

Based on the waveforms in Fig. 3 (a), $V_{\text {max_avg }}$ for the dc inductor, and the transformer windings are expressed as in (14) and (15).

$$
\begin{gathered}
V_{\max _{\_} a v g_{-} L d c}=2 \cdot \Phi \cdot\left(n V_{2}-V_{o}\right)+(1-2 \Phi) \cdot V_{o} \\
V_{\text {max_avg_Wprim }_{-}}=2 \cdot \Phi \cdot V_{2} ; \quad V_{\text {max }_{-} a v g \_W \mathrm{sec}}=2 \cdot \Phi \cdot n \cdot V_{2}
\end{gathered}
$$

Similarly, the rms current and peak voltage values for the input and output capacitors can be also calculated.

For the ac-inductor based topology, the inductor ripple cannot be neglected. To perform a fair comparison, the ac inductance value is taken as the maximum value that fulfills the condition $\Phi<\min [D,(1-D)]$ for the maximum output voltage and output power. The rms current of the ac inductance and the primary switches is calculated as in (16)-(17).

$$
I_{L a c, r m s}=I_{L a c p k} \sqrt{\frac{2}{3}(\Phi+\beta)}
$$

$$
I_{r m s_{-} S 1, S 2, S 3, S 4}=I_{L a c_{p k}} \sqrt{\frac{1}{3}(\Phi+\beta)}
$$

where the inductance peak value as well as the phase-shift and the discharge parameter are defined as in (18)-(20).

$$
\begin{gathered}
I_{L a c_{p k}}=\frac{-n V_{2}+V_{o}}{L_{a c}} \cdot \Phi T \\
\Phi=\frac{V_{o}}{\sqrt{2}} \sqrt{\frac{-k}{n V_{2}\left(V_{o}-n V_{2}\right)}} \\
\beta=\frac{n V_{2}-V_{o}}{V_{o}} \cdot \Phi
\end{gathered}
$$

The voltage stress in the inductor and transformer windings, as well as the capacitors rms current and peak voltages are calculated in the same way as in the dc-inductor counterpart.

Figure 4 presents the SCSF, WCSF and CCSF for the dcinductor based and ac-inductor based, respectively, for an output power varying from $P_{\text {out }}=100 \mathrm{~W}$ to $P_{\text {out }}=1 \mathrm{~kW}$ and an output voltage range from $V_{\mathrm{o}}=300 \mathrm{~V}$ to $V_{\mathrm{o}}=380 \mathrm{~V} @ V_{2}=100 \mathrm{~V}, D=$ 0.5 and $n=4$.

From the CSF analysis of Fig. 4 it can observed a large difference between the dc and ac-inductor based topologies. The CSF in the dc-inductor based topology present small variations over the whole range of output voltage and output power, while in the ac-inductor the worst condition occurs at the lower output voltage. In the ac-inductor based topology, the inductance value is adjusted for maximum output voltage and output power; therefore, as the output voltage decreases, the required phase shift value decreases and the inductance peak current increases, resulting in high rms currents, which gives the worst CSF case scenario. In the dc-inductor based topology, for a certain output voltage the values are independent of the operating power.

Figure 5 shows a comparison of the SCSF, WCSF and CCSF of the dc and ac-inductor based topologies as a function of the output power for a fixed output voltage of $V_{\mathrm{o}}=380 \mathrm{~V}$. As previously discussed, the major difference between CSF analysis of the two studied topologies is that in the dc-inductor based converter, for a certain output voltage, the CSF values remain constant with respect to the output power; however in the ac-inductor based converter varies as a function of the processed power. This is due to the fact that the output voltage is kept fixed and, therefore, in the dc-inductor based converter the phase shift value is constant (in ideal conditions where the leakage inductance is neglected). However, the phase shift value in the ac-inductor based converter is load dependent; in this case the inductance is designed for the maximum output power, which degrades the CSF at low output power.

The dc-inductor based topology presents lower SCSF and CCSF over the entire operating range even due to the large rms currents in the ac-inductor based topology for the same output power. However, the ac-inductor based converter shows lower WCSF at low power operation due to lower voltage stress on its windings compared to the dc-inductor based converter. At maximum output power, the dc-inductor based topology presents lower total CSF than the ac-inductor based converter. 


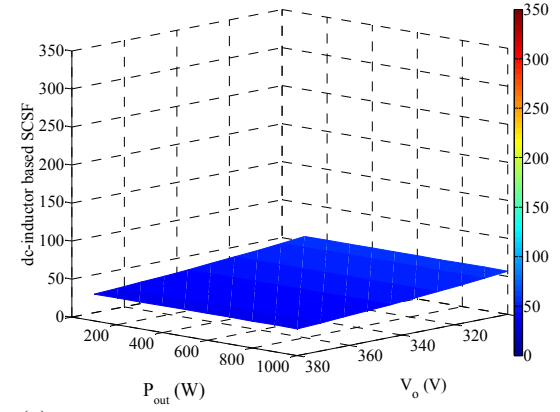

(a)

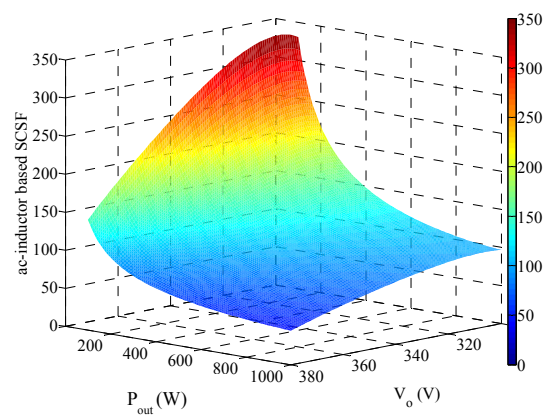

(d)

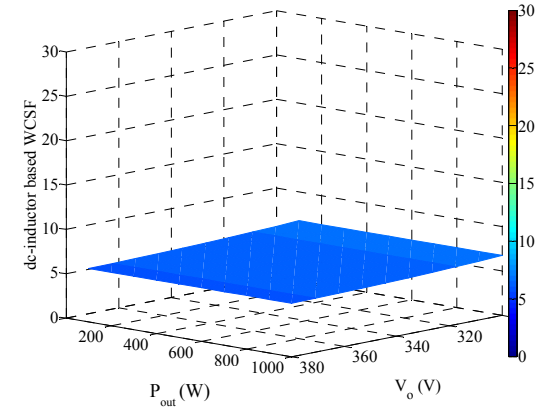

(b)

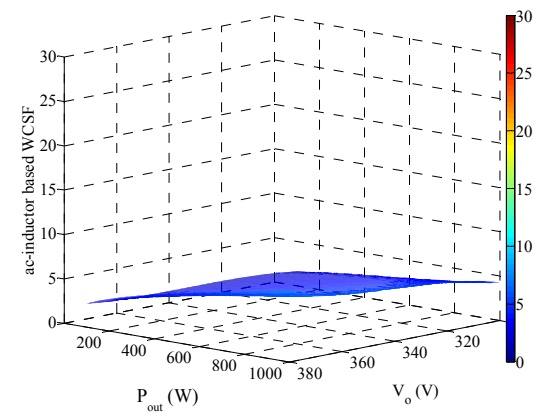

(e)

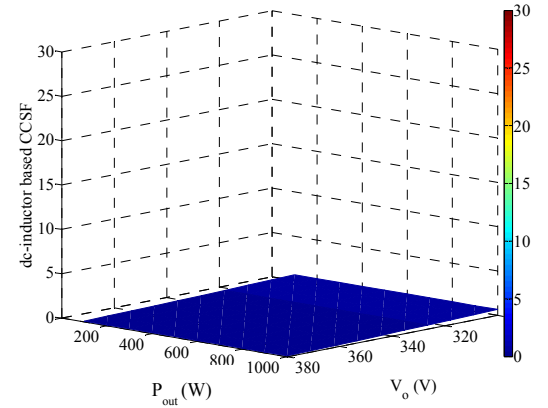

(c)

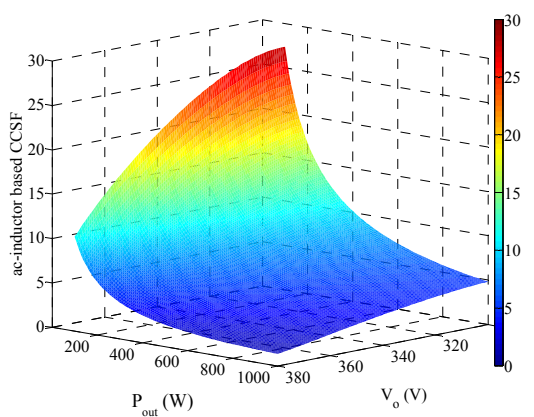

(f)

Fig. 4. Component stress factor of dc-inductor based converter: (a) SCSF, (b) WCSF and (c) CCSF and ac-inductor based converter (d) SCSF, (e) WCSF and (f) CCSF as a function of the output power $P_{\text {out }}$ and output voltage $V_{\text {o. }}$

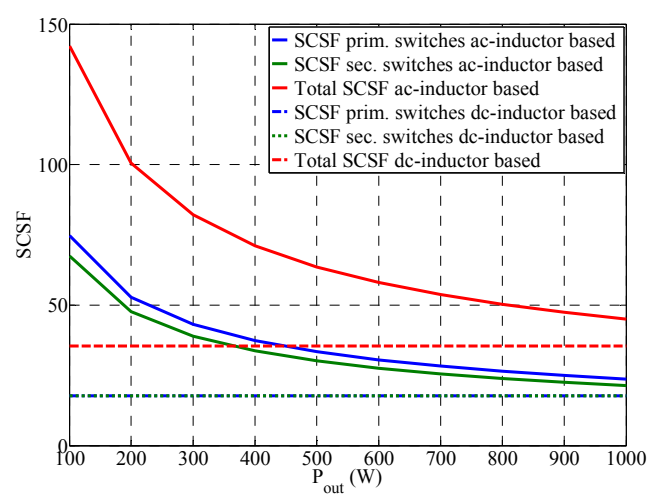

(a)

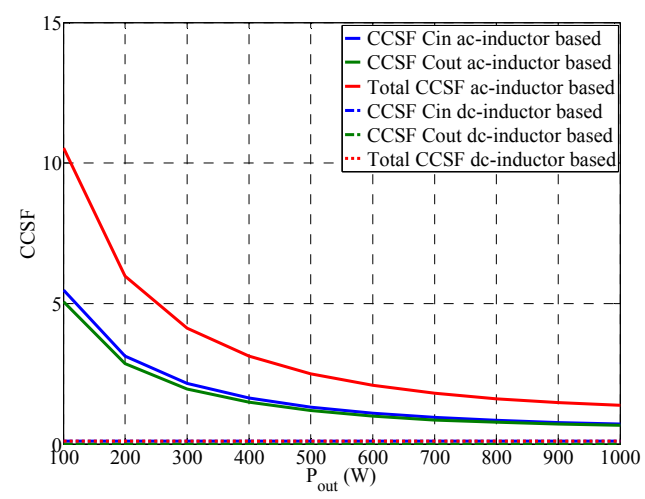

(c)

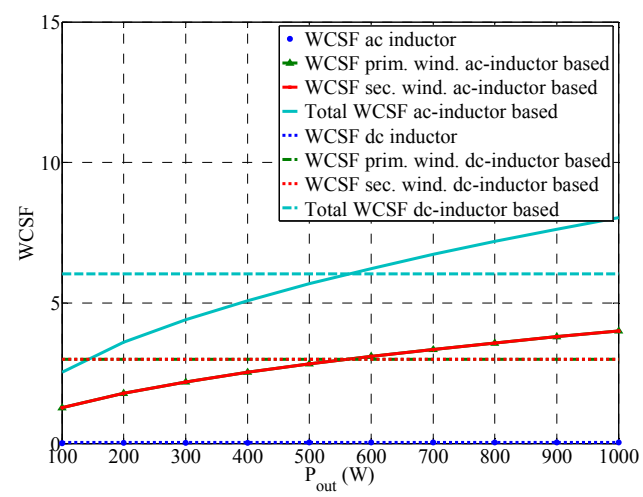

(b)

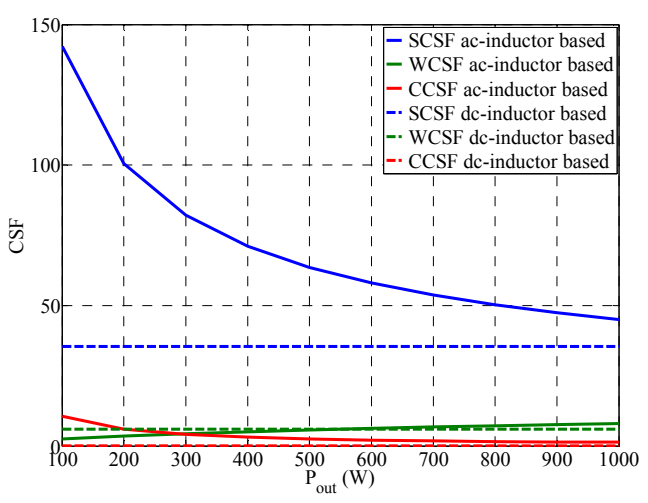

(d)

Fig. 5. Comparison of CSFs of dc and ac-inductor based topologies: (a) SCSF, (b) WCSF, (c) CCSF and (d) Total CSF for different $P_{\text {out }} @ V_{\mathrm{o}}=380 \mathrm{~V}$. 


\section{SOFT-Switching PERformances}

The zero-voltage switching (ZVS) operation for the lowvoltage side switches can be deduced on the precondition that the body diode of the MOSFET conducts before it is triggered.

For the dc-inductor based topology, ZVS operation is similar to the conventional PSFB converter. The addition of the two input inductor currents from the two-phase interleaved boost structure complicates the ZVS operation. However, the conclusion for the PSFB converter still holds, i.e. ZVS is load dependent and the ZVS range can be extended by an additional leakage inductance, which, on the other hand, will cause severe voltage overshoot and oscillation across the diodes located on the secondary side. Assuming $L_{1}=L_{2}=L$ and $L_{d c}$ is large enough, all the MOSFET can have the ZVS condition once (21) is satisfied.

$$
\left\{\begin{array}{c}
P_{1}>2 V_{2} \cdot\left(-n \cdot \frac{P_{o u t}}{V_{o}}-\frac{V_{1}(1-D) T}{2 L}+\frac{V_{2}}{L_{l k}} \cdot t_{d}\right) \\
P_{1}<2 V_{2} \cdot\left(n \cdot \frac{P_{o u t}}{V_{o}}+\frac{V_{1}(1-D) T}{2 L}-\frac{V_{2}}{L_{l k}} \cdot t_{d}\right)
\end{array}\right.
$$

where $t_{d}$ and $P_{\text {out }}$ represent the deadtime between high-side and low-side switches and the output power, respectively.

Even though the switch output capacitance is not considered in (21), as explained in [12], the larger the output capacitance, the longer the critical dead time leading to a reduced ZVS range.

For the ac-inductor topology, as discussed in [16], taking into account the amount of stored energy in the MOSFETs' output capacitance $\left(C_{\text {oss }}\right)$, all MOSFETs can obtain ZVS operation, if (22) is satisfied; in other words, during the deadtime there is significant energy stored in the ac inductor to charge/discharge the output capacitance of the MOSFETs triggered off.

$$
\left\{\begin{array}{l}
I_{L 1, \min }=\frac{P_{1}}{2 V_{1}}-\frac{V_{1}(1-D) T}{2 L}<0 \\
\left|I_{L 1, \min }\right|>\sqrt{\frac{\left(2 \cdot C_{o s s}\right) \cdot V_{2}^{2}}{L_{a c}}}
\end{array}\right.
$$

The ZVS range is reduced when the allowed current ripple is small. However, the high-side switches $S_{1}$ and $S_{3}$ can inherently achieve ZVS independent of the converter operating conditions. When $I_{L 1, \min }>0, S_{2}$ in the leading leg loses ZVS, but $S_{4}$ in the lagging leg can have ZVS if the constraints in (23) are satisfied.

$$
\frac{V_{o}-n V_{2}}{L_{a c}} \Phi T-\frac{P_{1}}{2 V_{1}}+\frac{V_{1}(1-D) T}{2 L}>\sqrt{\frac{\left(2 \cdot C_{o s s}\right) \cdot V_{2}^{2}}{L_{a c}}}
$$

Based on the analysis above, accordingly, the ZVS performance of the two topologies can be compared under the same operating conditions, as an example depicted in Fig. 9, where $V_{1}=50 \mathrm{~V}, V_{2}=100 \mathrm{~V}, V_{\mathrm{o}}=380 \mathrm{~V}, L_{1}=L_{2}=150 \mu \mathrm{H}, t_{d}=$ $50 \mathrm{~ns}$ and $C_{\text {oss }}=490 \mathrm{pF}$.

The diodes on the high voltage side can achieve zero-current switching (ZCS) in either dc or ac inductor based topologies. However, in the dc-based, as FBPS, when the current in the diodes decrease to zero, they become reverse-biased and thereby

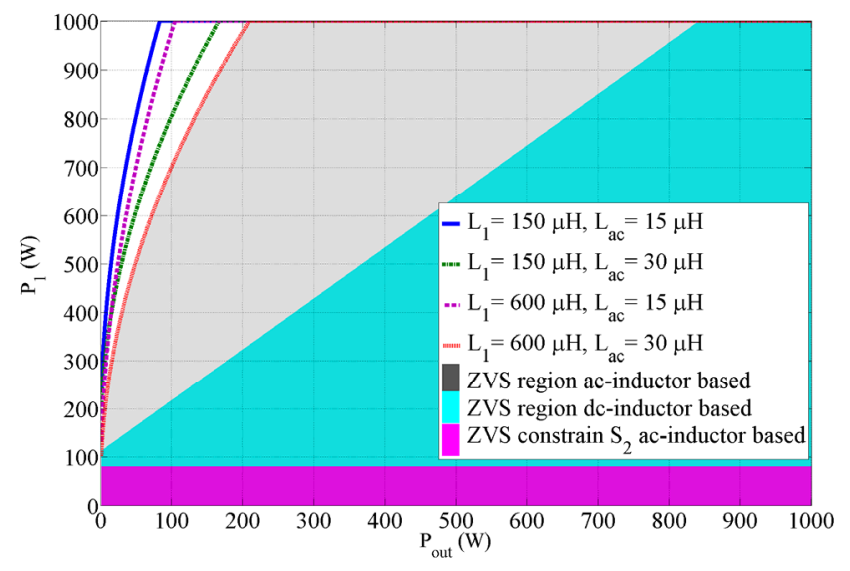

Fig. 9. Comparison of the ZVS ranges.

start to block voltage $n \cdot V_{2}$; however, the resonant circuit formed by the leakage inductance and the diode output capacitance begins to ring, which leads to a considerably high peak voltage in excess of $n \cdot V_{2}$ over the diodes. Therefore, voltage snubbers are necessarily added to protect the diodes from over-voltage breakdown. On the other hand, for the ac-inductor based, the diodes are fully clamped by the output capacitor, so that no voltage spikes exist, thus extra snubbers are not required.

\section{EXPERIMENTAL RESULTS}

The ac-inductor based topology is constructed with a fast prototyping technique. The specifications and the components used in the prototype are given in Table I. A digital signal processor (DSP) is employed to generate the PWM gate driving signals as well as to implement closed-loop control algorithms.

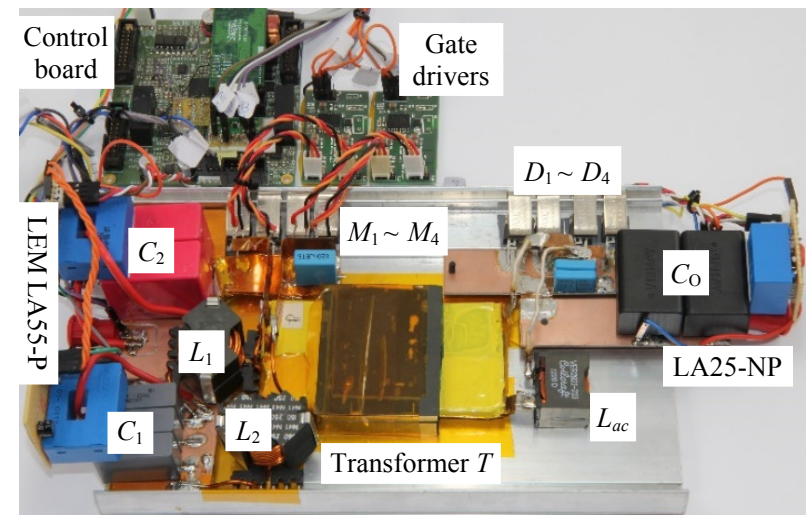

Fig. 10. Propotype of the ac-inductor based DI converter.

TABLE I. SPECIFICATIONS AND COMPONENTS

\begin{tabular}{cc}
\hline \hline Input voltage & $V_{1}=25 \sim 60 \mathrm{~V}$ \\
$V_{2} \max$ & $=120 \mathrm{~V}$ \\
\hline Output voltage & $V_{\mathrm{o}}=350 \sim 380 \mathrm{~V}$ \\
\hline Maximum output power & $P_{\text {out } \max }=1000 \mathrm{~W}$ \\
\hline Switching frequency & $60 \mathrm{kHz}$ \\
\hline Transformer & $4: 16$, ELP64/10/50, N87 \\
\hline ac inductor & $28 \mu \mathrm{H}$, VER2923-223 \\
\hline Inductor $L_{1}$ and $L_{2}$ & $155 \mu \mathrm{H}$, gapped RM12, N41 \\
\hline Semiconductor devices & IRFB4115, HFA08TB60 \\
\hline \hline
\end{tabular}




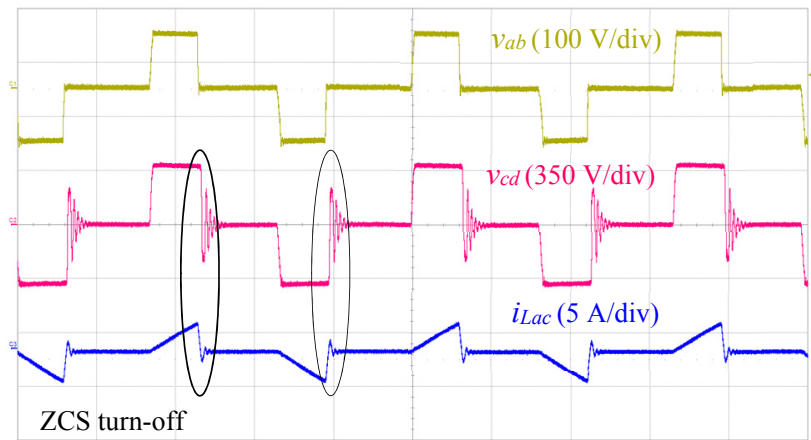

Fig. 11. Experimental results of the high frequency ac voltages $v_{a b}, v_{c d}$ and inductor current $i_{\text {Lac }}$ operating in dual input mode at $V_{1}=50 \mathrm{~V}, V_{2}=100 \mathrm{~V}, V_{o}=$ $370 \mathrm{~V}$ and $P_{\text {out }}=200 \mathrm{~W}$. Time scale: $5 \mu \mathrm{s} / \mathrm{div}$.

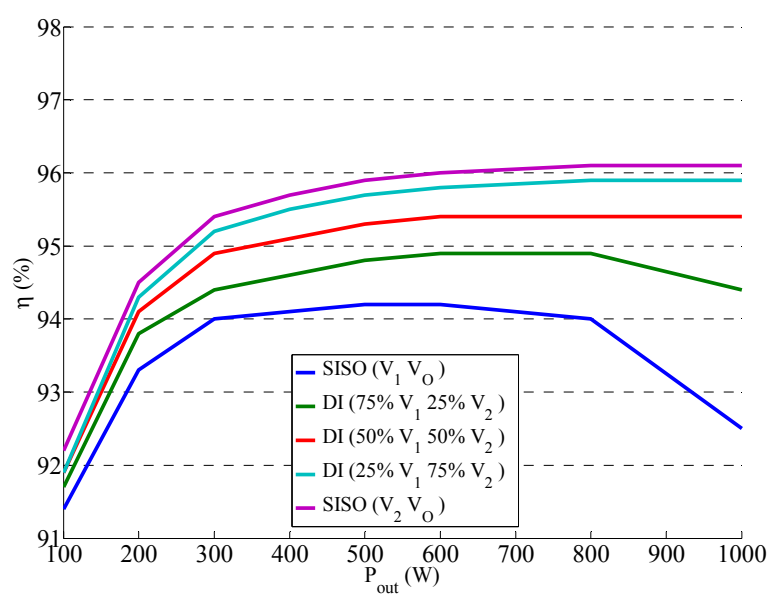

Fig. 12. Measured efficiency of the ac-inductor based dual input converter.

Typical experimental waveforms are measured and shown in Fig. 11, which can match with Fig. 3 (b) well, and therefore verifies the theoretical analysis.

The measured efficiency of the converter operating in dualinput mode (DI) and single-input single-output modes (SISO), for various power sharing between input ports $V_{1}$ and $V_{2}$, is plotted in Fig. 12, at $V_{1}=50, V_{2}=100 \mathrm{~V}$, and $V_{o}=370 \mathrm{~V}$. A peak efficiency of $97.5 \%$ is achieved. More detailed analysis about the experimental test on the ac-inductor based converter have been reported in [16].

\section{CONCLUSION}

In this paper, the dc-inductor and ac-inductor based DI or TPC, are compared in terms of component stress and softswitching performance. It can be seen that, due to the large output inductor, dc-inductor based topology has lower rms current than its ac-inductor based counterpart. However, the acinductor based switching performance is better than the dcinductor based due to larger ZVS range and lower voltage stress over the output rectifier. In fact, both dc and ac inductor based topologies are the very promising candidates for renewable energy applications. Furthermore, the dc-inductor based topology is favorable for high power application with a low output voltage below $100 \mathrm{~V}$; whereas the ac-inductor based converter would be a better choice for applications requiring a high switching frequency as well as a high output voltage above
$400 \mathrm{~V}$, for instance, a compact grid-connected power conversion system.

\section{REFERENCES}

[1] F. Blaabjerg, Z. Chen and S. B. Kjaer, "Power electronics as efficient interface in dispersed power generation systems," IEEE Transactions on Power Electronics, vol. 19, no. 5, pp. 1184 - 1194, 2004.

[2] Z. Chen, J. M. Guerrero and F. Blaabjerg, "A review of the state of the art of power electronics for wind turbines," IEEE Transactions on Power Electronics, vol. 24, no. 8, pp. 1859 - 1875, 2009.

[3] Z. Zhang, R. Pittini, M. A. E. Andersen and O. C. Thomsen, "A review and design of power electronics converters for fuel cell hybrid system applications," Energy Procedia, vol. 20, pp. 301-310, 2012.

[4] W. Zhang, D. Xu, X. Li, R. Xie, H. Li, D. Dong, C. Sun and M. Chen, "Seamless Transfer Control Strategy for Fuel Cell Uninterruptible Power Supply System," IEEE Transactions on Power Electronics, vol. 28, no.2, pp. $717-729,2013$.

[5] A. Tani, M. Camara, B. Dakyo and Y. Azzouz, "DC/DC and DC/AC Converters Control for Hybrid Electric Vehicles Energy ManagementUltracapacitors and Fuel Cell," IEEE Transactions on Industrial Informatics, vol. 9, no. 2, pp. 686 - 696, 2013.

[6] Y. Li, X. Ruan, D. Yang, F. Liu and C. K. Tse, "Synthesis of MultipleInput DC/DC Converters," IEEE Transactions on Power Electronics, vol. 25, no. 9, pp. 2372 - 2385, 2010.

[7] H. Al-Atrash, M. Pepper and I. Batarseh, "A Zero-Voltage Switching Three-Port Isolated Full-Bridge Converter," in 28th Annual InternationalTelecommunications Energy Conference, 2006. INTELEC, 2006.

[8] H. Al-Atrash and I. Batarseh, "Boost-Integrated Phase-Shift Full-Bridge Converter for Three-Port Interface," in 2313 - 2321, IEEE Power Electronics Specialists Conference PESC, 2007.

[9] Z. Zhang, O. C. Thomsen and M. A. E. Andersen, "Soft-switched dualinput DC-DC converter combining a boost-half-bridge cell and a voltagefed full-bridge cell," IEEE Transactions on Power Electronics, vol.28, no.11, pp. 4897-4902, Nov. 2013.

[10] H. Al-Atrash, F. Tian and I. Batarseh, "Tri-Modal Half-Bridge Converter Topology for Three-Port Interface," IEEE Transactions on Power Electronics, vol. 22, no. 1, pp. 341 - 345, 2007.

[11] Z. Qian, O. Abdel-Rahman, H. Al-Atrash and . I. Batarseh, "Modeling and Control of Three-Port DC/DC Converter Interface for Satellite Applications," IEEE Transactions on Power Electronics, vol. 25, no. 3, pp. $637-649,2010$.

[12] W. Li, J. Xiao, Y. Zhao and X. He, "PWM Plus Phase Angle Shift (PPAS) Control Scheme for Combined Multiport DC/DC Converters," IEEE Transactions on Power Electronics, vol. 27, no. 3, pp. 1479 - 1489, 2012

[13] H. Wu, P. Xu, H. Hu, Z. Zhou and Y. Xing, "Multiport Converters Based on Integration of Full-Bridge and Bidirectional DC-DC Topologies for Renewable Generation Systems," IEEE Transactions on Industrial Electronics, vol. 61, no. 2, pp. 856 - 869, 2014.

[14] Z. Zhang and M. Andersen, "Interleaved Boost-Half-Bridge Dual-Input DC-DC Converter with a PWM Plus Phase-Shift Control for Fuel Cell Applications," in 39th Annual Conference of the IEEE Industrial Electronics Society, IECON, 2013.

[15] M. C. Mira, Z. Zhang, A. Knott and M. A. E. Andersen, "Power Flow Control of a Dual-Input Interleaved Buck/Boost Converter with Galvanic Isolation for Renewable Energy Systems," in IEEE Applied Power Electronics Conference APEC, 2014.

[16] M. C. Mira, Z. Zhang, A. Knott and M. A. E. Andersen, "Analysis, design, modeling, and control of an interleaved-boost full-bridge three-port converter for hybrid renewable energy systems," IEEE Transactions on Power Electronics, vol. 32, no. 2, pp. 1138 - 1155, Feb. 2017.

[17] R. Pittini, M. C. Mira, Z. Zhang, A. Knott and M. A. E. Andersen, " Analysis and comparison based on component stress factor of dual active bridge and isolated full bridge boost converters for bidirectional fuel cells systems," In Proc. International Power Electronics and Application Conference and Exposition. 2014. 